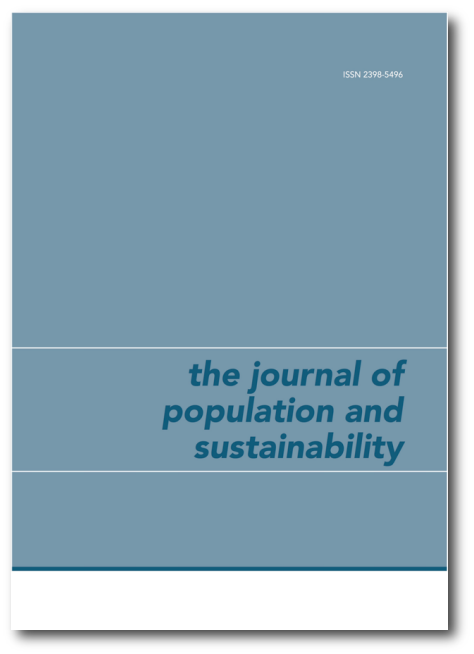

The Journal of Population and Sustainability

ISSN 2398-5496

Article title: Editorial introduction

Author(s): David Samways

Vol. 4, No. 2, 2020, pp.5-15

doi: 10.3197/jps.2020.4.2.5

Open Access - CC BY 4.0 


\title{
Editorial introduction
}

\author{
David Samways - Editor
}

The eighth issue of the JP\&S is published in the midst of the COVID-19 crisis. The $J P \& S$ will in due course have a special issue devoted to the role of population in pandemic risk, but for the present it is worth reflecting on how COVID-19 and global pandemics in general relate to population and environmental issues and in particular to some of the themes covered by the papers (mostly written well before the pandemic) in this issue.

The immediate impact of the pandemic and its management have rightly been the focus of concern, but the factors which led to the generation of the pandemic itself are also of great importance given the costs in terms of both human health and disruption to the lives of billions of people. The causes of the pandemic are multiple, but population growth and density are amongst the most significant. Along with specific consumption factors, the globalisation of the world economy and other elements of our socio-technical systems, the ever-growing entanglement of human populations with wild species has played a pivotal role in the generation of the current crisis.

As Ilan Kelman points out in his paper published here, the current pandemic is, like many so-called 'natural' disasters, not 'natural' at all but the result of our societal choices. In the case of COVID-19, the choices which have been significant are not limited to how we have dealt with the spread of the disease, but also include choices made in other spheres such as the economy, international development, socio-technical structures and so on that formed the unacknowledged conditions which facilitated the generation of the pandemic itself. At the micro level, many of these 'choices' may have been passively made, the outcome of deeply embedded social practices and ways of life, the taken-for-granted aspects of everyday life. For many of those whose direct entanglement with the natural 
world exposes them to zoonotic reservoirs, the social practices in which they are engaged are frequently well beyond the level of active choice. It is often the rural poor of the Global South who are most exposed as population growth and poverty lead them to clear forest and establish subsistence cultivation only to be later displaced by commercial interests (Carr, 2009; Lopez-Carr and Burgdorfer, 2013; Kong et al., 2019).

The trade in wildlife for bushmeat, traditional "medicines" and other cultural practices is also a factor in the spread of zoonoses. COVID-19 is believed to have originated in bats with the Malaysian pangolin, trafficked for use in traditional Chinese medicine, as an intermediary species (Ye et al. 2020; Wong et al. 2020). Among the many factors identified as drivers of the illegal wildlife trade, economic growth and globalisation are critical. In more developed countries the combination of population growth, urbanisation and increased affluence has fuelled demand while in poorer regions population growth and rural poverty are drivers of supply. Importantly, supply and demand have been connected by improved roads to formally inaccessible wilderness locations and trade routes to far away markets (Wolfe et al. 2005; Nijman, 2010; Rosen and Smith; 2010).

However, it would be mistaken to regard population, consumption (affluence), and technology (transportation systems) ${ }^{1}$ as simple drivers of our entanglement with nature and its associated risks. As Joel Cohen (2017) has argued, culture is a critical factor in how population, the economy and the environment articulate with each other (Fig. 1). Duffy et al. (2016) have argued that in respect of the hunting of endangered wildlife, poverty ${ }^{2}$ has been poorly conceptualised and that the motivations of individuals and social groups to hunt have frequently been reduced to an economic rationality. However, as they demonstrate, motivations for hunting often arise from deeply embedded social and cultural factors and that policies aimed at reducing hunting through financial incentives frequently fail or even unintentionally increase the ability to hunt or consume bushmeat.

1 As per Holdren and Ehrlich's (1971) impact = population $x$ affluence $x$ technology (IPAT).

2 Dufy et al. do not connect poverty with population growth, however it is nonetheless a crucial dimension (UNFPA 2014). 
Figure 1. Joel E. Cohen's (2010) tetrahedron conceptualising the interactions between population, environment, economy and culture.

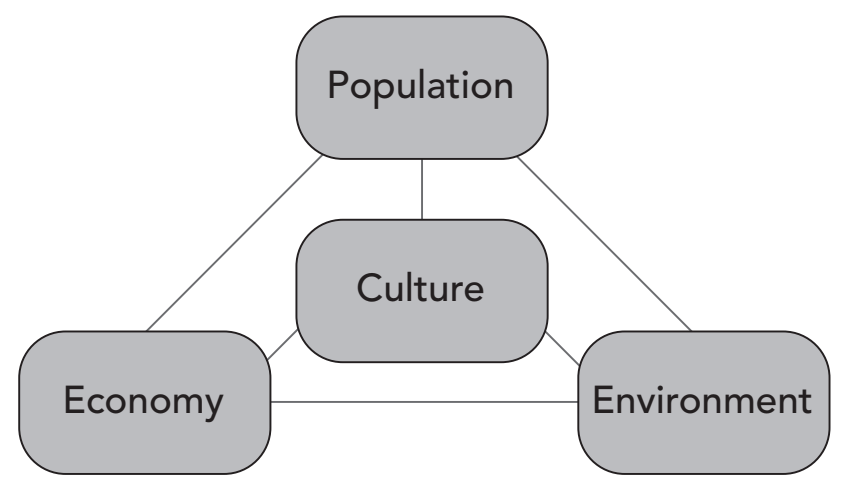

As a driver of human entanglement with nature, population growth itself also has important socio-cultural dimensions which are not generally modelled in standard demographic transition approaches where economic development is seen as the primary determinant of reduced fertility. In addition to the availability of sexual health services, female education, and the general reduction in poverty, social norms surrounding family size are an important determinant of fertility (Dasgupta and Dasgupta 2017). Influencing these social norms and fertility choices can take a variety of forms and social marketing methods have been employed successfully by the Population Media Centre (see Ryerson 2018) and are the subject of Sarah Baillie, Kelley Dennings and Stephanie Feldstein's article on the Centre for Biological Diversity's (CBD) Endangered Species Condom project in this issue.

As Baillie et al. show, social marketing is a means of "selling a social good as if it were a commodity". This structured, theoretically informed, approach has been successfully employed to address a range of social problems (notably to increase contraceptive use in India) and is employed by CBD not just as a means of reducing unplanned pregnancy in the US, but also to start a conversation about the impact of population growth on endangered species. Innovatively, Endangered Species Condoms use humour and art to connect sexual health choices with native wildlife species which are threatened directly by population growth. CBD recognises that in the US population growth is largely a consequence of immigration, but while the project is aimed at local reproductive choices the objective is global in that 
the project elevates the environmental consequences of population growth in public discourses with the aim of ultimately influencing policy makers and, equally importantly, the environmental NGOs which generally choose to ignore the issue.

Ilan Kelman's paper is concerned with the ability of society to cope with disaster. $\mathrm{He}$ argues that the vulnerability of a society to the environment or nature is consequent on societal choices which place people in harm's way. Demographic factors including population density can have both positive and negative effects. While high density urban areas are more likely to have emergency services that are experienced and well equipped, larger and more closely confined populations, as in the case of COVID-19, can exacerbate risks. As Jenny Goldie's review of Doug Kelbaugh's Urban Fix (published here) makes clear, the redesigning of the city may well offer opportunities for mitigating climate change and overpopulation. However, Kelbaugh's enthusiasm for high density urban living may be in question following the pandemic. With population density being a key factor in the spread of the virus, many who have become acclimatised to home working may well be reassessing the advantages, costs and risks of urban living.

Worldwide, populations are moving from rural to urban locations and it is this internal migration that accounts for the majority of all the world's migration (IOM 2020). Currently, just over half the global population live in urban areas, but it is anticipated that by 2050 this number will rise to 68\% (UN, 2018). The COVID-19 pandemic has made the extent of internal migration extremely clear as migrant workers lose their livelihoods and, en masse, have been forced to return to their region of origin. The International Labour Organisation estimates that 1.6 of the 2 billion people who work in the world's informal economy (nearly half the global workforce) have been severely affected by the pandemic lockdown. The majority of these workers are in the Global South with women being disproportionately affected compared to men (ILO, 2020).

This latter aspect of the consequences of the pandemic chimes well with Ilan Kelman's observations regarding the gendered dimensions of disasters. In terms of fatalities men appear to be disproportionately affected by COVID-19 (Jin et al. 2020), but evidence suggests that in social and economic terms women will be disproportionately affected (ILO, 2020; UN, 2020). Kelman argues that it is gender differentiated roles rather than inherent qualities that frequently make women 
more vulnerable to disasters. This is certainly the case with the consequences of COVID-19: women generally earn less and save less than men, they are often in more insecure employment, are more likely to be heads of single parent households, the burden of unpaid care work largely falls on them, and on top of this they are more likely to experience greater levels of domestic violence during lockdown. From the perspective of population growth the disruption to sexual health services may result in increased fertility. In the Caribbean and Latin America it is estimated that 18 million women will lose regular access to contraception as a result of the pandemic (UN, 2020). The disruption to sexual health services represents an immediate threat, but the economic impact upon women in the Global South represents a longer-term risk of stalling the progress made on increasing fertility choices.

The role of internal migration on urban expansion and population density are themes of Ripan Debnath's contribution to this issue. Exploring the effect of land use change on local climate in Dhaka, Bangladesh, Debnath models the impact of rural to urban migration on the rapid growth in Dhaka city and shows, through the analysis of satellite images and geographic, demographic and climatic data, that such growth will adversely impact the future urban climate. While influenced by global and regional climate change, local land cover change will be an additional exacerbating factor. Land use change from agricultural to urban will result in both heat stress and flooding which will disproportionately affect the most recent and poorest migrants who tend to live in low-lying areas. Like Kelman and Kelbaugh, Debnath argues that the worst effects of such disasters can be avoided with the right urban planning policy choices. However, like Kelbaugh, Debnath sees so called 'smart growth' principles involving, amongst other things, higher density development as a possible solution to Dhaka's population growth. Undoubtedly, Debnath and Kelbaugh are correct about better management and higher density housing being a means of mitigating the impact of climate change, but the COVID-19 pandemic has demonstrated the adage that where it comes to environmental problems "there's no such thing as a free lunch" and the solution to one problem frequently leads to the creation of other unanticipated consequences.

Migration is also a major theme of Travis Edwards and Luis Gautier's article for this issue of the JP\&S which examines the relationship between carbon dioxide 
emissions and population. Where previous studies have concentrated on per capita carbon dioxide emissions, Edwards and Gautier are concerned with how increases in population and the use of alternative energy sources affect total emissions in the USA where immigration is the main driver of population growth. Edwards and Gautier propose a new model where the Demographic Transition Model (DTM) (the idea that as countries develop population growth rises and then falls), and IPAT ${ }^{3}$ are integrated into the Environmental Kuznets Curve (EKC) (the inverted $U$ shaped graph that frequently shows that as wealth increases pollution at first rises and then falls). They argue that the concentration on per capita emissions in most of the EKC literature fails to acknowledge population growth can lead to increases in total emissions even when per capita emissions are falling. As a major contributor to the reduction in per capita carbon emissions, Edwards and Gautier go on to estimate a threshold of alternative energy generation after which total emissions may fall. Furthermore, following their proposed DTM-IPATEKC model, they argue that the shift in lifestyle that immigrants experience as they move from low/medium income countries into high-income countries may contribute to total emissions growth, however this will depend on the level of alternative energy present in the destination country. They suggest that at present the rate of growth of alternative energy generation in the US is insufficient to offset population growth.

Edwards and Gautier note that, since their study considered total carbon dioxide emissions rather than consumption-based emissions, future research should address this. This would raise some interesting questions since research examining the effect of immigration on $\mathrm{CO}_{2}$ emissions tends, not unreasonably, to assume that with rising income migrant consumption conforms to the higher levels of the destination country (see for example Weber and Sciubba 2018; Cafaro and Götmark 2019). However, this assumption is open to question since it is well established that remittances from migrants to their country of origin represent around three times the value of official development aid (Ratha et al. 2016) and migrant saving levels are also significant (De et al. 2014). Such income use will have an obvious impact on immigrant consumption levels, but also shifts our understanding of migration towards a global developmental perspective. Remittances represent a significant contribution to development which can have environmentally beneficial effects (Hecht et al. 2006; Jaquet et al. 2016; Oldekop

3 See note 2. 
et al. 2018; but see also Davis and Lopez-Carr for a more ambiguous account) and under some circumstances lead to lower fertility (Anwar and Mugha 2016; Green et al. 2019; Paul et al. 2019. See also Ifelunini et al. 2018 for an account of increased fertility with remittance receipt). While the impact of remittances on both environmental impact and fertility is complex and uneven it would appear that the evidence supports a potentially positive impact if other structures (education systems and sexual health services for example) are present. Again, the consequences of the COVID-19 pandemic are pertinent here. As a consequence of the lockdown and probable economic recession in rich countries, remittances to the low and middle-income countries are likely to fall as migrants lose their jobs. The World Bank (2020) estimates that remittance flows to low and middleincome countries are likely to fall by around $20 \%$ at a time when need will be greatest and foreign direct investment is likely to fall by around $35 \%$. The longerterm impact on both human wellbeing, population growth and environmental impact will depend on the actions of countries in the Global North. The impact of COVID-19 came after the submission of Edwards and Gautier's paper, but their conclusion is prescient:

The ability to collectively lower our environmental impact in both advanced and developing economies is vital to the future of the planet. Implementing effective environmental and economic policies which can be strategically enacted for specific stages of development, to reduce overall environmental degradation while maintaining an acceptable standard of living, is crucial to this task.

In the post-pandemic world attention to the welfare of people in developing countries is in the interest of us all.

\section{References}

Anwar A.I., Mughal, M.Y., 2016. Migrant remittances and fertility. Applied Economics. DOI: 10.1080/00036846.2016.1139676

Cafaro, P., Gotmark, G., 2019. The potential environmental impacts of EU immigration policy: future population numbers, greenhouse gas emissions and biodiversity preservation. The Journal of Population and Sustainability. 4(1), pp. 71-101. 
Carr, D. 2009. Population and Deforestation: why rural migration matters. Progress in Human Geography, 33(3), pp. 355-378.

Cohen, J.E., 2010. Population and climate change. Proceedings of the American Philosophical Society. 154(2), pp. 158-182

Cohen, J.E., 2017. How many people can the Earth support? The Journal of Population and Sustainability. 2(1), pp. 37-42.

Dasgupta, A., Dasgupta, P., 2017. Socially embedded preferences, environmental externalities, and reproductive rights. Population and Development Review 43(3), pp. 405-441.

Davis, J., Lopez-Carr, D., 2010. The effects of migrant remittances on population - environment dynamics in migrant origin areas: international migration, fertility, and consumption in highland Guatemala. Population and Environment. 32, pp.216-237. DOI:10.1007/s11111-010-0128-7

De, S., Ratha, D., Yousefi, S.R., 2014. A note on international migrants' savings and incomes. [pdf] Washington D.C.: World Bank. Available at: https://blogs. worldbank.org/sites/default/files/Note\%20on\%20Diaspora\%20Savings\%20 Sep\%2023\%202014\%20Final.pdf [Accessed 15 June 2020].

Duffy, R., St John, F.A.V., Büscher, B., Brockington, D., 2016. Toward a new understanding of the links between poverty and illegal wildlife hunting. Conservation Biology. 90(1), pp.14-22. DOI: 10.1111/cobi.12622

Ehrlich, P.R., Holdren, J.P., 1971. Impact of population growth. Science, New Series. 171(3977), pp. 1212-17.

Green, S.H., Wang, C., Ballakrishnen, S.S., Brueckner, H., Bearmand, P., 2019. Patterned remittances enhance women's health-related autonomy. SSM Population Health. 9, 100370. https://doi.org/10.1016/j.ssmph.2019.100370

Hecht, S.B. Kandel, S., Gomes, I., Cuellar, N., Rosa, H., 2006. Globalization, forest resurgence, and environmental politics in El Salvador. World Development. 34(2), pp.308-323. doi:10.1016/j.worlddev.2005.09.005

Ifelunini, I.A., Ugwu, S.C., Ichoku, H.E., Omeje, A.N., Ihim, E., 2018. Determinants of fertility rate among women in Ghana and Nigeria: implications for population growth and sustainable development. African Population Studies. 32(2)(S.2). 
ILO, 2020. ILO Monitor: COVID-19 and the world of work. Third edition. [pdf] Geneva: International Labour Organization. Available at: https://www.ilo.org/ wcmsp5/groups/public/---dgreports/---dcomm/documents/briefingnote/ wcms_743146.pdf [Accessed 4 May 2020]

IOM 2020. World migration report 2020. [pdf] Geneva: International Organization for Migration. Available at: https://publications.iom.int/system/files/pdf/ wmr_2020.pdf [Accessed 11 June 2020].

Jaquet, S., Shrestha, G., Kohler, T., Schwilch, G., 2016. The effects of migration on livelihoods, land management, and vulnerability to natural disasters in the Harpan Watershed in Western Nepal. Mountain Research and Development, 36(4) pp.494-505 https://doi.org/10.1659/MRD-JOURNAL-D-16-00034.1

Jin J.M., Bai P., He W., Wu F., Liu X.F., Han D.M., Liu S., Yang J.K., 2020. Gender differences in patients with COVID-19: focus on severity and mortality. Frontiers in Public Health Vol. 8 Article 152. https://doi.org/10.3389/fpubh.2020.00152

Kong, R., Diepart, J., Castella, J., Lestrelin, G., Tivet, F., Belmain, E., Bégué, A., 2019. Understanding the drivers of deforestation and agricultural transformations in the Northwestern uplands of Cambodia. Applied Geography, 102(1), pp.84-98.

Lopez-Carr, D., Burgdorfer, J., 2013. Deforestation drivers: Population, migration, and tropical land use. Environment, 55(1) pp. 3-11.

Nijman, V., 2010. An overview of international wildlife trade from Southeast Asia. Biodiversity and Conservation, 19, pp.1101-1114. https://doi.org/10.1007/ s10531-009-9758-4

Oldekop, J.A., Sims, K.R.E., Whittingham, M.J., Agrawala, A., 2018. An upside to globalization: international outmigration drives reforestation in Nepal. Global Environmental Change, 52 pp.66-74. https://doi.org/10.1016/j. gloenvcha.2018.06.004

Paul, F.H., Talpur, G.H., Soomro, R., Marri, A.A., 2019. The impact of remittances on fertility rate: evidence from Pakistan. Sindh University Research Journal (Science Series). 51(01), pp.129-134. http://doi.org/10.26692/sujo/2019.01.23 
Ratha, D., De, S., Plaza, S. Schuettler, K., Shaw, W., Wyss, H., Yi, S. 2016. Migration and Remittances - Recent Developments and Outlook. Migration and Development Brief 26, April 2016, Washington, DC: World Bank. DOI: 10.1596/ 978-1-4648-0913-2

Rosen, G.E., Smith, K.F., 2010. Summarizing the Evidence on the International Trade in Illegal Wildlife. EcoHealth 7, pp.24-32. https://doi.org/10.1007/s10393010-0317-y

Ryerson, W. N., 2018. The hidden gem of the Cairo consensus: helping to end population growth with entertainment media. The Journal of Population and Sustainability. 2(2), pp. 51-61.

UN, 2018. 68\% of the world population projected to live in urban areas by 2050, says UN. [online] New York: United Nations. Available at: https://www.un.org/ development/desa/en/news/population/2018-revision-of-world-urbanizationprospects.html [Accessed 13 June 2020].

UN, 2020. Policy brief: the impact of COVID-19 on women. [pdf] New York: United Nations. Available at: https://www.un.org/sexualviolenceinconflict/wp-content/ uploads/2020/06/report/policy-brief-the-impact-of-covid-19-on-women/policybrief-the-impact-of-covid-19-on-women-en-1.pdf [Accessed 13 June 2020]/

UNFPA (United Nations Population Fund), 2014. Population and poverty. [online] New York: UNFPA. Available at: https://www.unfpa.org/resources/populationand-poverty [Accessed 12 June 2020]

Weber, H., Sciubba, J.D., 2018. The effect of population growth on the environment: evidence from European regions. European Journal of Population, [e-journal] April 9, 2018. https://doi.org/10.1007/s10680-018-9486-0

Wolfe, N. D., Daszak, P., Kilpatrick, A. M., \& Burke, D. S., 2005. Bushmeat hunting, deforestation, and prediction of zoonoses emergence. Emerging infectious diseases, 11(12), pp.1822-1827. https://doi.org/10.3201/eid1112.040789

Wong, G., Bi, Y-H., Wang, Q-H., Chen, X-W., Zhang, Z-G., Yao, Y-G., 2020. Zoonotic origins of human coronavirus 2019 (HCoV-19 / SARS-CoV-2): why is this work important? Zoological Research. doi: 10.24272/j.issn.2095-8137.2020.031 
World Bank, 2020. COVID-19 crisis through a migration lens. Migration and development brief 32. [pdf] Washington D.C.: World Bank Group. Available at: http://documents.worldbank.org/curated/en/989721587512418006/pdf/COVID19-Crisis-Through-a-Migration-Lens.pdf [Accessed 2 June 2020]

Ye, Z. W., Yuan, S., Yuen, K. S., Fung, S. Y., Chan, C. P., Jin, D. Y., 2020. Zoonotic origins of human coronaviruses. International journal of biological sciences, 16(10), 1686-1697. https://doi.org/10.7150/ijbs.45472 